\title{
Ciencia y novedad en la prensa oficial. La Gaceta de Madrid (1759-1770)
}

\author{
EnRIQUe MANERo RuIZ-SaLdaña \\ UNED
}

\begin{abstract}
RESUMEN
Es un lugar común que la prensa fue un vector del ideario ilustrado. En España la prensa privada, que emergió con vigor en

el siglo XVIII, tuvo, sin embargo, diversos escollos que sortear (entre ellos: la escasa duración que tuvieron las publicaciones).

La Gaceta de Madrid, como publicación vinculada a la Secretaria de Estado, gozó de protección gubernamental y sostenimiento en el tiempo. El presente. articulo trata de demostrar que este periódico, además de ser un prontuario de información oficial, participó de algunos aspectos del ideario ilustrado: interés por

la ciencia, utilitarismo tecnológico, etc. Asi, pudo jugar un papel en la difusión de ideas modernas. Para alcanzar nuestro objetivo hemos seleccionado noticias de astronomia, expediciones, experimentalismo, academias cientificas, inventos; también las informaciones de hallazgos arqueológicos.
\end{abstract}

ABSTRACT

It is a commonplace that press heralded the Enlightenment ideology. In Spain, private press emerged vigorously in the Eighteenth Century. However it had to overcome several obstacles (among them: the short duration of newspapers in street). On the other hand, the Gaceta de Madrid, as a paper close to the Secretaria de Estado, had governmental protection and enjoyed time stability. Taken into account these aspects, the article tries to verify that this newspaper, besides its official target, was involved in the Enlightenment program of scientific promotion, interest in technology, etcetera; and therefore could play a role in the widespread diffusion of modern values. To achieve our target, we have selected news concerning astronomy, expeditions, experimentalism, scientific academies, inventions and archaeological findings.

\section{INTRODUCCIÓN}

Es un lugar común que la prensa en el Setecientos fue un vector de nuevas ideas. La Gaceta de Madrid, como periódico gubernamental, pasa por ser un prontuario de información oficial. Sin embargo, escrutando su información y utili- 
zando como miradores de mentalidad privilegiados la ciencia y la novedad (con el abrigo de este concepto analizaremos el interés por la tecnología y por lo arqueológico), repararemos en que es algo más que una relación de información políticodiplomática. Para contextualizar lo analizado en este artículo, trazaremos una sucinta historia de la Gaceta de Madrid; también en bosquejo, referiremos las ventajas de que gozó dicho periódico (de aqui colegiremos la importancia de la prensa oficial como propagador de nuevas ideas; en este caso: ciencia y novedades). Tras hacer un somero estado de la cuestión, se planteará la idea revisionista de repensar la Gaceta en clave divulgadora de algunos aspectos del ideario ilustrado, que eventualmente convertirá al periódico en algo más que una relación informativa de índole oficial. Ésta será la hipótesis esgrimida, que se circunscribe al periodo comprendido entre 1759 y 1770, el tramo inicial del reinado de Carlos III.

La Gaceta de Madrid pertenece al género periodístico del «gaceterismo» informativo. Nace en 1661 como consecuencia de la colaboración entre Juan José de Austria y Fabro Bremundan (se llamó Gazeta Nueva al principio; desde abril de 1697 se denominará Gaceta de Madrid). El privilegio de impresión estuvo vinculado de 1690 a 1697 al Hospital General de Madrid, que asi subvenía a sus gastos. En 1697 Goyeneche adquirió dicho privilegio real, confirmado en Real Cédula de 1701 por Felipe $V$. Sabemos que en 1710 se imprimía en casa de Juan de Ariztia; luego en la calle de Alcalá, y posteriormente en la Red de San Luis. En 1762 Carlos III incorpora a la Corona el privilegio de impresión, dirigiendo la publicación Francisco Manuel de Mena (calle Carretas). Con éste, se operaron reformas técnicas en la imprenta además de regularse la jornada laboral. Desde enero de 1775 la Gaceta de Madrid se imprime en la Imprenta del Rey (a partir de 1781 Imprenta Real). Es concebido como periódico de noticias político-militares y guía de publicaciones de la época. Se publica los martes, y desde septiembre de 1778 también los viernes. Los contenidos arquetípicos de la Gaceta de Madrid son noticias internas políticas, diplomáticas, bélicas; también de sociedad, sucesos y señaladamente información exterior tomada de las gacetas europeas (la Gazette francesa, la de Amsterdam, la de Bruselas, etc.), esta última normalmente en régimen de intercambio o pago. En la época analizada los redactores-traductores fueron Juan Antonio de Eguilondo y Jacinto Ventura Melendreras ${ }^{1}$.

Liminarmente, tenemos que preguntarnos acerca de las posibilidades de difusión de las noticias espigadas para nuestro análisis. La Gaceta de Madrid ofrece estabilidad en el tiempo frente a la corta duración de las publicaciones privadas, sometidas éstas a un férreo régimen jurídico restrictivo (licencia y censura previas al permiso de publicación que concede el Consejo de Castilla). Dicho sostenimiento en el tiempo desde 1661 (con alguna salvedad en su primera época del XVII) se enfatiza en 1762, cuando se convierte en instrumento del poder borbónico a fuer de

- Cf. Agullar Piñal, F., La prensa española en el siglo xvil. Diarios, revistas y pronósticos. Madrid, 1978; Eivciso Recio, L. M., Cuentas del "Mercurio" y la "Gaceta”. Valladolid, 1957; Gómez Aparicio, P., Historia del periodismo español. Desde la Gaceta de Madrid (1661) hasta el destronamiento de Isabel II. Tomo I. Madrid, 1967. 
su vinculación orgánica a la Secretaría de Estado. Sabemos que la Gaceta en 1781 tenía una tirada de 10.072 periódicos por número, vendiéndose por suscripción en el mismo año el $18,7 \%{ }^{2}$. Compárese, verbigracia, con la modesta tirada de El Censor. sólo 500 ejemplares ${ }^{3}$. A mayor abundamiento, la importancia divulgativa del periódico analizado dimana del hecho de que hubo ciudades que no tuvieron prensa hasta muy avanzado el Setecientos (o hasta los albores del XIX). Sabemos, además, que los suscriptores de la Gaceta se localizaban en 527 localidades ${ }^{4}$, predominando en las ciudades y villas $(83,1 \%)^{5}$. En cuanto a la extracción social de aquéllos, Elisabel Larriba mantiene que las clases medias emergentes son mayoría entre los abonados, bien que la prensa llegó a todos los sectores de la socie$\mathrm{dad}^{6}$. La importancia difusora de nuestro periódico también le viene de los abonos en grupo y del préstamo de las publicaciones; aspectos que junto a la atenta escucha en cafés y tertulias pudieron ser cauterio contra el alto precio de los periódicos y contra el inveterado analfabetismo, cuya tasa global a finales del XVIII estaria en torno al $55,97 \%$ según Jacques Soubeyroux $x^{7}$. El factor lectura en voz alta ha de ser tenido en cuenta, puesto que esta práctica estaba extendida en la España del tiempo ${ }^{8}$. En una línea parecida, y en un contexto europeo, dice Thomas Munck:

«... the common practice of reading papers aloud in cafés and clubs still ensured widespread dissemination of some kind in the more heavily populated areas»".

Por todo ello la Gaceta de Madrid se erige con un protagonismo sin parangón en lo que respecta a las posibilidades de divulgación de noticias y de los valores que subyacen en ellas.

Debemos esbozar un breve estado de la cuestión. Interesa destacar que la bibliografía que trata aspectos del XVIII suele subrayar el papel de periódicos como EI Pensador (1762), del anglófilo Clavijo y Fajardo, paladín de la crítica de la sociedad y sus costumbres; o el de El Censor (1781), del liberal Cañuelo, que recibe la influencia periodística del Spectator (1711) de Addison. De la Gaceta de Madrid frecuentemente se realza su carácter de prontuario de información oficial: ambigús palaciegos, noticias políticas y diplomáticas, audiencias regias, diario de operaciones bélicas, nombramientos, etcétera. Veamos algunus botones de muestra. Richard Herr considera a los periódicos como «conductos de la llustración» de la me-

${ }^{2}$ LaRRIBA, E., Le Public de la presse en Espagne à la fin du XVIIIe siècle (1781-1808). Paris, 1998, p. 63.

3 Agullar Piñal, F., Introducción al siglo XVIII. Madrid-Gijón, 1991, p. 156.

4 Laraiba, E., Le Public..., p. 63.

5 LaRRIBA, E., Le Public..., p. 66.

${ }^{6}$ Laraiba, E., Le Public..., p. 331

7 SoubeYroux, J., «Niveles de alfabetización en la España del siglo xvili. Primeros resultados de una encuesta en curso", Revista de Historia Moderna. Anales de la Universidad de Alicante, n. ${ }^{\circ} 5$ (1985), pp. 159-172 (cita en p. 166).

${ }^{8}$ LaRRIBA, E., Le Pubilic..., p. 30.

${ }^{9}$ MunCK, Th., The Enlightenment. A comparative social history. 1721-1794. London, 2000, p.131. 
socracia emergente; de la Gaceta de Madrid hace una escueta mención, sin comentario añadido ${ }^{10}$. Paul-J. Guinard, en su señero texto, arguye que la Gaceta y el Mecurio histórico y político fueron heraldos de información de índole política y militar. Le cito a la letra:

«... le monopole, qu'elle partagera toutefois avec le Mercurio quand celui-ci naîtra, de la diffusion des novelles politiques et militaires" ${ }^{11}$.

John Lynch se refiere a la prensa como «canal de difusión de la llustración», pero señaladamente se refiere a El Pensador, a El Censor, a El Correo de Madrid y al Semanario Erudito ${ }^{12}$. Francisco Sánchez-Blanco sostiene que la prensa dieciochesca española tuvo gran importancia debido a que:

"La nación o la opinión no poseen otra institución mediante la cual articularse como no sean los periódicos, ya que no existen asambleas ni parlamentos regionales ${ }^{13}$.

Con todo, es muy crítico respecto del reinado de Carlos III al que tilda de «regalismo despótico " ${ }^{14}$, enfatizando la labor, durante la época, de un periódico ilustrado: El Censor, que fue paradigmático debido a su carácter crítico y renovador.

Plantearemos la hipótesis que se trata de defender. Es cierto que la Gaceta de Madrid y el Mercurio histórico y político tuvieron el monopolio de las noticias políticas y militares. Sin embargo, escrutando la Gaceta vemos que tiene una atención multifocal, que la información es miscelánea. Los dos miradores elegidos para analizar las noticias (ciencia y novedad) actúan como lupa de aumento: harán aflorar de la publicación cuestiones de mentalidad ilustrada. El periódico oficial no es una publicación científica, ni tecnológica, ni erudita; pero la inclusión de un elenco informativo imbuido de axiomas como la observación, el experimentalismo, la cooperación científica, la invención humana y lo "curioso" de los hallazgos arqueológicos nos lleva a pensar en una elección orientada de noticias; esto es, preocupación estatal por estos temas, selección con sesgo ideológico. Concluiremos que la Gaceta participa del interés en el acontecer científico y novedoso: es testigo de valores ilustrados tales como el empirismo científico, que venia madurando desde el XVII, y el utilitarismo («culto de lo útil» en palabras de Sarrailh); también participa la publicación de una renovada curiosidad por conocer aspectos arqueológicos. Por otro lado, la difusión del periódico fue grande, como se apuntó anteriormente, y bien pudo generar una opinión favorable a la ciencia y tecnología, además de ser una fuente insustituible para conocer algunas cosas que aconte-

10 Herr, R., España y la revolución del siglo xvil. Madrid, 1979, p. 151

11 Guinard, P.-J., La presse espagnole de 1737 à 1791. Formation et signification d'un genre. Paris, 1973, p. 112.

12 LYNCH, J., La España del siglo XVII. Barcelona, 1999, p. 231.

13 Sanchez-Blanco, F., El Absolutismo y las Luces en el reinado de Carlos III. Madrid, 2002, p. 59.

14 SánChez-Blanco, F., El absolutismo..., p. 347. 
cían fuera de la Monarquía. Resumiendo la hipótesis: la Gaceta de Madrid, sin perjuicio de ser un prontuario de información oficial, también fue vector de ciencia y novedades útiles y curiosas. Debiera añadirse que la elección orientada de noticias es un trasunto de "la política voluntarista de los agentes de la llustración", tomando en préstamo la expresión de Michel Vovelle ${ }^{15}$.

\section{LA CIENCIA}

En la centuria ilustrada las disciplinas de la ciencia no están cumplidamente delimitadas: no existe la profesión específica de científico ${ }^{16}$. Con todo, no es difícil identificar las actividades de sesgo científico de la época. A este respecto, la $\mathrm{Ga}$ ceta de Madrid refiere señaladamente noticias relacionadas con la astronomia (pasos de Venus por el disco solar, descripción de auroras boreales, etc.), con la navegación (aspectos tocantes a la determinación de la longitud marítima), con las expediciones, con el experimentalismo (y gusto por la física experimental), con las actividades de academias científicas y militares, etc.

En lo que respecta a la astronomía, las noticias más representativas son las que refieren aspectos de los pasos de Venus por el disco solar de 1761 y 1769 . La observación de aquéllos, como comprobaremos en la Gaceta, representó "el primer proyecto de colaboración e investigación científica del mundo occidental ${ }^{17}$. También, a través del periódico se ven las relaciones que tuvieron astronomía y navegación, relatándose los contactos que hubo entre los científicos para estudiar la determinación de la longitud en el mar, con mención expresa al cronómetro de Harrison.

Por otro lado, la Gaceta de Madrid se hace eco de algunas exploraciones de la época, sobremanera de las patrocinadas por Catalina II de Rusia, de las británicas, de la que comisionó la Corona danesa al Levante, Arabia y Persia, asi como de la española comandada por Gaspar de Portolá a la Alta California; todo ello inscrito en una característica del Setecientos: la expedición como institución, reflejándose en el periódico, además, las tipologías de este tipo de empresa del siglo (científica, de límites, misional). Asimismo, y en relación con los objetos acopiados en las exploraciones, el semanario participa noticias en las que se alude a los gabinetes de curiosidades, refiriéndose el interés de diplomáticos y príncipes en rendir visita a las colecciones de historia natural. También, el periódico oficial comunica informaciones de índole cartográfica, en un momento en que la política reformista exigía "una cartografía fiable de España» ${ }^{18}$, aunque debiera añadirse que las noticias de este tenor son casi todas foráneas.

15 Vovelle, M. (ed.), El hombre de la llustración. Madrid, 1995, p. 19.

16 Ferrone, V., «El cientifico", en M. Vovelle, (ed.), El hombre..., p. 221

1 BeRnABÉu AlBefT, S., «La expedición hispano-francesa a medir el paso de Venus", en $M$. Sellés y otros (comps.), Carlos III y la ciencia de la llustración Madrid, 1988, p.316.

18 CAPEL, H., Geografia y matemáticas en la España del siglo xvil. Barcelona, 1982, p. 135. 
Por otra parte, la Gaceta de Madrid presta atención a las actividades de las academias científicas, ya que la renovación de la ciencia se gestó extramuros de la Universidad; en palabras de Salvador Albiñana: «llustración y Universidad no tienden a ser realidades convergentes " ${ }^{19}$. En esta línea de pujanza académica, hay que destacar que el periódico oficial refiere algunos experimentos que se realizaron al abrigo de las academias científicas y observatorios de la marina, en los que es patente el afán del siglo XVIII por las mediciones. En lo que respecta a las academias nacionales, hay que señalar el eco periodistico que tuvo la labor de algunas instituciones de fundación ilustrada, como la Real Academia Geográfico-Histórica de Caballeros de Valladolid (1752), que a su carácter aristocrático (congregaba a la primera nobleza de la ciudad castellana) unía un interés erudito y científico. La Gaceta de Madrid menciona los discursos y disertaciones que allí se pronunciaron, estilos literarios típicos de las producciones intelectuales de estos foros, y que prueban el auge de que gozó la «prosa de ideas» en el Dieciocho ${ }^{20}$. Además, la Gaceta refiere noticias de algunas academias militares, circunscritas a lo que se ha venido en llamar "militarización» de la ciencia ilustrada ${ }^{21}$; así, por ejemplo, las informaciones provenientes de la Academia de Artillería de Segovia (1764) reflejan algunos aspectos de la innovación científica. También se ve en el periódico oficial el interés de las nuevas instituciones del Setecientos por la actualización de la docencia científica, que se detecta en los exámenes de los alumnos de la Sociedad Bascongada de Arnigos del País (1765), en los cursos impartidos en el Real Seminario de Nobles de Madrid (1725) y en algunos anuncios de lo que hoy llamaríamos clases particulares.

Por el contrario, las informaciones de la Gaceta referidas al alma máter suelen aludir a besamanos y otros asuntos alejados de la nueva mentalidad. Ejemplo de esto es la noticia que refiere que Carlos III admitió a besamanos a la Universidad de Salamanca, que acudió al acto con sus comisarios; o la información que comunica el besamanos al que asistió la Universidad de Valencia con motivo de la exaltación al Trono del monarca ${ }^{22}$.

La conjunción de Venus con el disco del Sol prevista para el 6 de junio de 1761 fue seguida por la Gaceta de Madrid. El periódico en una primera noticia refiere que Delisle, miembro de la Academia de las Ciencias de París, ha presentado al rey de Francia un Mapa-Mundi en el que "se demuestra el paso que ha de hacer el planeta Venus sobre el Sol „23. Otra noticia se hace eco de que Lalande, también miembro de la mencionada academia, presenta a Luis XV un libro de astronomía que trata de los movimientos celestes, del paso de Venus sobre el Sol, refiriéndo-

\footnotetext{
19 Albiñana, S., Universidad e Ilustración. Valencia en la época de Carlos III. Valencia, 1988, p. 234.

20 Álvarez de Miranda, P., “Ensayo», en F. Aguilar Piñal (ed.), Historia literaria de España en el siglo XVIII Madrid, 1996, pp. 296 y 297.

21 LAFUente, A., y PESET, J. L., "Las actividades e instituciones científicas en la España ilustrada", en M. Sellés y otros (comps.), Carlos III y la ciencia..., pp. 39, 40 y 41.

22 Gaceta de Madrid n. 3 del 15 de enero de 1760 y Gaceta... n. ${ }^{\circ} 14$ del 1 de abril de 1760.

23 Gaceta... n. 21 del 20 de mayo de 1760, data Paris 3 de mayo de 1760.
} 
se asimismo que incorpora cálculos astronómicos de utilidad para navegantes, además de un método para determinar la longitud en el mar mediante observaciones lunares ${ }^{24}$. El periódico nos participa, por otra parte, una data que cuenta que los miembros de la academia científica parisina Pingré y Chappe d'Auteroche, a fin de valorar cuáles son los "parajes más propios" para la observación del paso de Venus, se dirigirian respectivamente a la isla Rodríguez en el océano Índico y a Siberia vía San Petersburgo, añadiéndose que Rusia habia cursado una petición a la academia parisina para que enviara un astrónomo con el objetivo de llevar a cabo la mencionada observación astronómica ${ }^{25}$. La Gaceta de Madrid también informa en otra noticia del ingreso del jesuita italiano Boscovich en la Sociedad Real de Londres, mencionándose que sus obras de «Physica» habían sido la carta de presentación que le había franqueado las puertas de una expedición para observar el paso de Venus delante del Sol${ }^{26}$. Sabemos también por una data de la publicación que Cassini de Thury, de la Académie des Sciences, se había desplazado a Austria para observar desde alli la conjunción de Venus con el Sol. En otra noticia se nos refiere que el astrónomo mencionado tiene el cometido adicional de verificar las tablas de Cassini, su difunto padre, añadiéndose que el archiduque José habia acompañado al sabio francés en dicha observación, realizada en Luxemburgo, Austria, a las cuatro de la mañana ${ }^{27}$. Por otro lado, una noticia francesa comenta que los astrónomos habian podido ver a Venus en su "emersión", después de que las nubes que habia a las seis y media de la mañana del 6 de junio de 1761 se hubieran disipado. Otra información, detallada y explicativa, proveniente de Francia refiere los lugares de observación y sus protagonistas: Maraldi en el Observatorio Real, Fouchy y Ferner en el palacio de La Muette, Delisle en la abadia de Santa Genoveva, el abad Lacaille en Conflans, los padres Merville y Clouet en el Colegio Luis el Grande y Libour y Messier en el Observatorio de la Marina; matizándose además tres cosas: la primera es que, según Lalande, destacado en el palacio de Luxemburgo, la conjunción de Venus en su totalidad se había producido a las 6:52 horas de la mañana, la segunda es que el padre Merville habia utilizado un "telescopio newtoniano de 6 pies" y la tercera es que la utilidad de la observación sería grande, puesto que el cotejo con las observaciones realizadas en otros puntos ayudaría a conocer la distancia de la Tierra al Sol ${ }^{28}$. Por otra parte, la Gaceta de Madrid nos comunica en una data que en Copenhague se había verificado el fenómeno del paso de Venus por el disco del Sol, a pesar de las nubes de aquel 6 de junio de 1761. Más explícita es la noticia de dicho paso en Suecia, ya que conocemos por una noticia del periódico que la reina y el príncipe heredero sueco habian acompañado en sus observaciones a los astrónomos escandinavos: War-

${ }^{24}$ Gaceta... n. ${ }^{\circ} 30$ del 22 de julio de 1760 , data París 5 de julio de 1760.

25 Gaceta... n. ${ }^{\circ} 45$ del 4 de noviembre de 1760 , data Paris 18 de octubre de 1760.

26 Gaceta... n. ${ }^{\circ} 4$ del 27 de enero de 1761, data Londres 2 de enero de 1761.

${ }^{27}$ Gaceta... n. 22 del 2 de junio de 1761 , data Paris 16 de mayo de 1761 y Gaceta... n. 28 del 14 de julio de 1761, data Viena 15 de junio de 1761.

${ }^{28}$ Gaceta... n. ${ }^{2} 26$ del 30 de junio de 1761, data París 13 de junio de 1761 y Gaceta... n. ${ }^{2} 27$ del 7 de julio de 1761, data Paris 20 de junio de 1761. 
gentin, que habia utilizado un "anteojo de veinte pies", Klingenstierna, que había usado el "anteojo de Dollond de diez pies", y Wilke, que había observado con un telescopio newtoniano de dos pies ${ }^{29}$.

La Gaceta de Madrid también se hace eco del paso de Venus por el disco del Sol previsto para junio de 1769. Así, refiere el periódico que Lalande había presentado al rey de Francia un mapa de dicho fenómeno, con una memoria en la que se justificaba la utilidad de organizar viajes $a d h o c^{30}$. También cuenta la Gaceta en otra data que Catalina II de Rusia había escrito una carta en marzo de 1767 dirigida al presidente de la Academia de Ciencias Rusa, en la que la emperatriz recomendaba expresamente tres cosas: que la Academia "haga observar con cuidado" el paso de Venus de 1769, que se señalaran los parajes más apropiados para la observación y que si la Academia no contaba con suficientes astrónomos se encargase la operación a personas experimentadas de la Marina ${ }^{31}$. Asimismo, otra noticia del periódico nos comunica que las academias científicas de París y Londres, para verificar dicho feriómeno, habían comisionado astrónomos, que habrían de partir para México, Perú, Chile, Californias e islas del Pacífico; y que ambas instituciones habían aconsejado a su homóloga de Estocolmo que nombrara astrónomos para ir a la Laponia sueca a observar el paso de Venus ${ }^{32}$. De parecido tenor informativo es una noticia que cuenta que la Real Academia de Ciencias de Estocolmo ha comisionado a dos miembros con el cometido de observar el fenómeno del paso de Venus: uno iría a Laponia, con la tarea añadida de confeccionar un mapa marítimo del golfo de Botnia; el otro habría de ir a Finlandia, "hacia los confines de la Laponia rusa» ${ }^{33}$. En otra noticia, el periódico señala que ha zarpado de Plymouth una chalupa con astrónomos para seguir el paso de Venus, informándose además que el plan de navegación consistiría en ir al «mar del Sur», lugar elegido para los estudios, vía Madeira y cabo de Hornos $^{34}$. Por otro lado, la Gaceta de Madrid participa en una data la muerte del abate Chappe d'Auteroche «de una enfermedad inflamatoria y epidémica», cuyos estragos también habían afectado a Doz y Medina, los comisionados españoles para estudiar el paso de Venus («encargados de hacer la misma observación»); asegurándose que el 3 de junio de 1769 se había hecho la observación, "pero no se sabe si se habrán conservado sus papeles» 35 .

La Gaceta de Madrid también reflejó el interés científico por los eclipses. Así, una detallada y precisa noticia refiere que el abate Clouet, de la Academia de Ciencias de Ruán, había viajado a Madrid para observar el «eclipse anular de Sol» que se habia producido el 1 de abril de 1764, comentándose que las nubes habian

29 Gaceta... n. ${ }^{\circ} 29$ del 21 de julio de 1761, data Hamburgo 28 de junio de 1761 y Gaceta... n. ${ }^{\circ} 30$ del 28 de julio de 1761, data Hamburgo 5 de julio de 1761.

30 Gaceta... n. 22 del 29 de mayo de 1764 , data Versalles 12 de mayo de 1764.

31 Gaceta... n. 23 del 9 de junio de 1767, data Hamburgo 8 de mayo de 1767.

32 Gaceta... n. ${ }^{\circ} 13$ del 29 de marzo de 1768, data Estocolmo 19 de febrero de 1768.

33 Gaceta... n. 43 del 25 de octubre de 1768, data Estocolmo 16 de septiembre de 1768.

34 Gaceta... n. ${ }^{\circ} 41$ del 11 de octubre de 1768, data Londres 16 de septiembre de 1768.

35 Gaceta... n. ${ }^{\circ} 14$ del 3 de abril de 1770, data Paris 19 de marzo de 1770. 
impedido ver el principio del eclipse (pero cree que debió de ser a las 8 horas y 15 minutos), que el diámetro "entero" de la Luna había estado sobre el Sol durante 4 minutos y 23 segundos, y que había finalizado a las 11 horas y 24 minutos; añadiéndose, además, que el abate francés había utilizado para sus observaciones una péndola con minutos y segundos construida por Diego Rostriaga, y que el astrónomo informaría de todo ello a las academias con las que tuviera correspondencia ${ }^{36}$. La Gaceta alude en otra información al eclipse de Sol del 5 de agosto de 1766, contándose que Luis XV habia acompañado a su relojero Pedro Leroy en las observaciones astronómicas, realizadas con la ayuda de un anteojo acromático de Dollond de "diez a doce pies", añadiéndose que el rey habia departido con su acompañante acerca de la construcción del reloj para determinar la longitud en el $\operatorname{mar}^{37}$.

La Gaceta recoge algunas datas con noticias de cometas. Así, una información de sesgo descriptivo participa las caracteristicas de un cometa descubierto por el astrónomo francés Messier, diciéndose que parece casi tan grande como Júpiter, que está rodeado de nebulosidades, y que puede percibirse a simple vista entre las diez de la noche y el amanecer. Una noticia complementaria refiere que Messier presenta al rey de Francia un mapa celeste en el que se representa la ruta del astro aludido, estudiado en el Observatorio de la Marina parisino entre el 8 de agosto y el 16 de septiembre de 1769 , en que habia dejado de ser visible ${ }^{38}$.

También se hace eco el periódico de las auroras boreales en informaciones breves, descriptivas y marcadamente pseudocientíficas. Así, una noticia explica el meteoro luminoso observado en París: de "magnitud extraordinaria, y de mucha duración», con "muchos rayos de luz" de "color de fuego" que "se elevaban a una altura muy considerable sobre el horizonte». Desde Nápoles, por otra parte, nos participan ura noticia que describe el ambiente previo a una aurora boreal, diciéndose que se habia experimentado "un excesivo y extraordinario frío, producido por el continuo soplar del viento boreal, con nubes errantes, y algunos copos de nieve". En Parma, la data relata la aurora boreal refiriendo que se había extendido desde el Este al Norte, dividiéndose en rayos y columnas de luz de vistosos colores; y que había desaparecido a mediancche entre el Oeste y el Norte. Finalmente, una noticia con dato cuantitativo proveniente de Austria describe la aurora boreal como una brillante luz que habia cubierto el cielo, llegando el termómetro Réaumur a $3^{\circ}$ bajo cero ${ }^{39}$.

Otra preocupación patente en la Gaceta de Madrid fue la determinación de la longitud en el mar. Así, en una noticia se cuenta que Camus, de la Academia de

${ }^{36}$ Gaceta... n. ${ }^{\circ} 15$ del 10 de abril de 1764

${ }^{37}$ Gaceta... n. ${ }^{\circ} 34$ del 26 de agosto de 1766, data Paris 11 de agosto de 1766.

36 Gaceta... n. ${ }^{\circ} 37$ del 12 de septiembre de 1769, data París 28 de agosto de 1769 y Gaceta... n. 42 del 17 de octubre de 1769, data parís 2 de octubre de 1769.

${ }^{39}$ Gaceta... n. ${ }^{\circ} 46$ del 14 de noviembre de 1769, data París 30 de octubre de 1769; Gaceta... n. ${ }^{\circ} 7$ de 13 de febrero de 1770, data Nápoles 23 de enero de 1770; Gaceta... n. 7 del 13 de febrero de 1770, data Parma 23 de enero de 1770 y Gaceta... n. ${ }^{\circ} 8$ del 20 de febrero de 1770 , data Viena 20 de enero de 1770. 
Ciencias de París, y el relojero Berthoud han acudido a Londres para escuchar una disertación sobre el cronómetro de Harrison. En otra información, la Gaceta refiere la estancia de Camus y Lalande en Inglaterra, comisionados por el rey de Francia para el estudio de cuestiones concernientes a la longitud marítima, comentándose también que un francés residente en Londres había presentado a los mencionados astrónomos y a La Condamine al Rey Jorge III. Por otro lado, una noticia del periódico participa la reunión mantenida en el Almirantazgo de Londres por los comisarios de la longitud, que habian aprobado unas tablas marítimas útiles para solucionar el problema de la longitud marítima con la ayuda de "observaciones hechas en la Luna", indicándose que se experimentarian las tablas mencionadas a la mayor brevedad. Asimismo, otra data nos informa del viaje que, para estudiar la determinación de longitudes, habian hecho Pingré y Leroy a Haarlem, Leyden y La Haya, en las Provincias Unidas, donde habian recibido el apoyo de los anfitriones, añadiéndose que, por su parte, Messier estaba trabajando en el Almirantazgo de Amsterdam ${ }^{40}$.

La Gaceta de Madrid muestra interés en el relato de algunas expediciones rusas de la época. Por ejemplo, refiere el periódico que la Emperatriz Catalina II de Rusia proyecta un segundo viaje desde Kamchatka al mar del Sur y al Japón «para adelantar los descubrimientos anteriores". También, en una noticia de la Gaceta se comenta otra expedición, protagonizada por seis habitantes de la región de Kamchatka que navegando durante cuatro años por la zona habian descubierto dieciséis islas, cuyos habitantes formaban parte de la nación de los esquimales; destacándose que se habían enviado los mapas del viaje a los archivos de Moscú. Además, la Gaceta refiere en una data otro viaje, el de unos mercaderes de Kolima que habian descubierto unas islas ricas en pieles de zorro negro en la zona de las Aleutianas; añadiéndose que Catalina II había enviado allí tropas y geógrafos al mando del teniente coronel Blenmer, que la Compañia de Mercaderes Rusos de Kamchatka también había llegado a las islas y que suponía un inconveniente la distancia desde San Petersburgo a esos territorios. Finalmente, una información del periódico alude a otra expedición, señalándose que Lomonosov «ha formado el proyecto" de intentar llegar a la América septentrional vía océano Glacial Ártico, pertrechándose para ello dos fragatas que pasarían el invierno en la península de Kola hasta que, en la primavera, pudieran hacerse a la vela ${ }^{41}$.

El periódico también menciona de forma sucinta algunas exploraciones británicas. Una primera expedición reseñada en una data del periódico alude a que un navio gubernamental inglés viaja a América con ingenieros y dibujantes para "re-

40 Gaceta... n. ${ }^{\circ} 20$ del 17 de mayo de 1763, data Paris 2 de mayo de 1763; Gaceta... n. ${ }^{\circ} 26$ del 28 de junio de 1763, data Londres 3 de junio de 1763; Gaceta... n. ${ }^{\circ} 34$ del 20 de agosto de 1765, data Londres 26 de julio de 1765 y Gaceta...n. ${ }^{\circ} 32$ del 11 de agosto de 1767, data Amsterdam 23 de julio de 1767.

${ }^{41}$ Gaceta... n. ${ }^{\circ} 18$ del 3 de mayo de 1763, data Moscú 19 de marzo de 1763; Gaceta... n. ${ }^{\circ} 21$ del 22 de mayo de 1764, data San Petersburgo 3 de abril de 1764; Gaceta...n. ${ }^{\circ} 14$ del 2 de abril de 1765, data San Petersburgo 12 de febrero de 1765 y Gaceta... n. ${ }^{\circ} 44$ del 30 de octubre de 1764, data San Petersburgo 11 de septismbre de 1764 . 
conocer y levantar planos del Canal de Bahamas y Golfo de Florida». También sabemos de otro viaje gracias a una noticia de la Gaceta, que dice que el gobernador de la Florida Occidental, William Johnson, está pertrechando un navío en cuya tripulación habrá dibujantes, teniéndose la intención de "reconocer zonas del estrecho de Florida, de Florida y del Golfo de México". Además, una data londinense menciona otra expedición, refiriéndose que en Inglaterra se habían aprestado fragatas de guerra para ir a la "Isla de Falkland", en el «Mar Magallánico", a fin de consolidar los establecimientos británicos en la zona, comentándose también que el capitán Gordon, ingeniero del rey, estaba recorriendo la América meridional en misión de fijación de límites. Asimismo, otra noticia inglesa cuenta que el capitán Byron, en su segunda circunnavegación, ha descubierto en el mar del Sur una isla «situada a poca diferencia en la latitud de la California». En esta línea de informaciones, la Gaceta de Madrid participa una data del viaje de circunnavegación de Cook, refiriéndose que la Corona británica había pensionado al discípulo de Linneo, el naturalista sueco Solander, en misión astronómica y de observaciones de Historia Natural ${ }^{42}$.

También se hace eco el periódico de algunas expediciones francesas. Así, sabemos a través de una noticia que Bougainville habia arribado al puerto de SaintMalo, contándose que traía noticias del mar dei Sur, en el que destacaba una isla fértil de «singular bondad de las costumbres de sus moradores»; añadiéndose que había venido con la expedición un habitante de la zona, al que el explorador calificaba de muy inteligente y con algún conocimiento de astronomia. De forma complementaria, una breve noticia refiere que Luis XV había recibido de Bougainville el diario manuscrito de la circunnavegación con los pormenores del viaje $e^{43}$.

La Gaceta de Madrid dedicó cuatro noticias a la expedición científica y arqueológica programada por el gobierno danés a Arabia y Persia (1761-1767), dirigida por Karsten Niebuhr. En una primera noticia se nos refiere que las "personas doctas" comisionadas por el gobierno danés para la expedición han obtenido los pasaportes de la Sublime Puerta para llegar a Alejandría, desde donde se dirigirían a El Cairo y al monte Sinai para copiar inscripciones antiguas, añadiéndose que los pensionados debían recorrer también la Arabia Feliz. Una segunda noticia participa que la Corte danesa ha recibido cartas de Niebuhr escritas en Persépolis, en las que se cuenta que había reconocido las ruinas de esta ciudad durante quince días y, también, que la expedición había sufrido en el golfo Pérsico a causa de los violentos huracanes y de los piratas; comentándose, además, que tenían intención de ir a Shiraz e Ispahán. Una tercera data refiere que Niebuhr había escrito una carta desde Alepo, en Siria, relatando que había visitado Chipre, Tierra Santa, Jerusalén, Damasco, Tripoli

42 Gaceta... n. ${ }^{\circ} 6$ del 5 de febrero de 1765 , data Londres 11 de enero de 1765; Gaceta... n. 18 del 6 de mayo de 1766, data Londres 11 de abril de 1766; Gaceta.. n. ${ }^{\circ} 45$ del 10 de noviembre de 1767, data Londres 16 de octubre de 1767; Gaceta... n. ${ }^{\circ} 28$ del 15 de julio de 1766, data Londres 20 de junio de 1766 y Gaceta... n. 43 del 25 de octubre de 1768, data Estocolmo 16 de septiembre de 1768.

${ }^{43}$ Gaceta... n. ${ }^{\circ} 15$ del 11 de abril de 1769, data Paris 27 de marzo de 1769 y Gaceta... n. 46 del 14 de noviembre de 1769, data Fontainebleau 28 de octubre de 1769. 
y Latakia, y que había determinado gracias a observaciones astronómicas la posición de parte de las costas de Siria, cosa «que no se había hecho hasta ahora». Por último, gracias a una noticia procedente de Constantinopla sabemos que Niebuhr se encuentra en la capital otomana ya de regreso a Copenhague, señalándose que el sabio había tenido el cometido de «hacer averiguaciones útiles y curiosas» en la Arabia Feliz ${ }^{44}$.

Además, el periódico dedica espacio a la expedición española dirigida por Gaspar de Portolá. Una única noticia a este respecto señala que, en 1769 , dos nuevas expediciones "de Mar y Tierra" habían partido del cabo de San Lucas y del presidio de Loreto hacia California a fin de hacer diversos «reconocimientos» y establecer misiones para evangelizar a los «indios gentiles», de los que se elogiaba su «mansedumbre y buena índole» 45 .

La Gaceta de Madrid presta atención a la confección de mapas, dado el interés del XVIII por conocer el territorio. Así, sabemos por el periódico que Cassini de Thury colabora en la mejora de los mapas de Austria cartografiando las cercanías de Viena, donde utiliza el método de la triangulación. Otra noticia refiere que Cassini de Thury y Camus, que trabajaban en el mapa de Francia, habian presentado al Rey Luis XV la Hoja 58 del mapa galo (Colmar, Schlettstadt y parte de los Vosgos) y la 59, que comprendía Bugey, País de Gex y Ginebra. En esta línea de interés cartográfico, una noticia francesa nos informa que Pingré, canónigo regular de Santa Genoveva, y Latré, grabador, habían participado a Luis XV y a su real familia un plano de la ciudad de Pekín, que incluia memoria de su fundación, datos históricos y descripción de la ciudad. Por otro lado, la Gaceta cuenta en otra data que Guy de Mornas, geógrafo real francés, había presentado veintinueve mapas, que se unían a su Atlas Histórico y Geográfico que en ese momento llevaba cuatro volúmenes ${ }^{46}$. Además, el periódico es testigo de la colaboración científica, ahora en la cartografía, al referir, por ejemplo, una noticia en la que se dice que el profesor Euler es el destinatario de un mapa que le envían de San Petersburgo con los descubrimientos cartografiados por los navegantes rusos en las costas de América del Norte y de Siberia. De parecido tenor es una data prusiana que cuenta que la Academia de Ciencias de Berlín había recibido una carta de la Emperatriz Catalina II de Rusia, en la que expresaba su deseo de ser útil a las ciencias y las artes, y en cuyo post scriptum se incluían dos mapas nuevos «y muy exactos»: uno del mar Caspio y otro del curso del Volga ${ }^{47}$.

${ }_{44}$ Gaceta... n. ${ }^{\circ} 6$ del 9 de febrero de 1762 , data Copenhague 24 de diciembre de 1761; Gaceta... n. ${ }^{\circ}$ 48 del 26 de noviembre de 1765, data Copenhague 26 de octubre de 1765; Gaceta... n. 11 del 17 de marzo de 1767, data Copenhague 3 de febrero de 1767 y Gaceta... n. 17 del 28 de abril de 1767, data Constantinopla 2 de marzo de 1767.

45 Gaceta... n. 50 del 11 de diciembre de 1770, data México 16 de agosto de 1770.

46 Gacela... n. ${ }^{\circ} 33$ del 18 de agosto de 1761, data Viena 18 de julio de 1761; Gaceta... n. ${ }^{\circ} 1$ del 5 de enero de 1762, data París 19 de diciembre de 1761; Gaceta... n. 16 del 16 de abril de 1765, data Versalles 30 de marzo de 1765 y Gaceta... n. ${ }^{\circ} 24$ del 14 de junio de 1768 , data Versalles 25 de mayo de 1768.

47 Gaceta... n. ${ }^{\circ} 12$ del 25 de marzo de 1766, data Berlín 24 de febrero de 1766 y Gaceta... n. 21 del 24 de mayo de 1768, data Berín 23 de abril de 1768. 
El periódico relata concisamente noticias relacionadas con las visitas realizadas a los gabinetes de curiosidades. Así, sabemos gracias a una noticia que Achmet Efendi, ministro de la Sublime Puerta, durante un viaje diplomático a Prusia rinde visita al gabinete de curiosidades berlinés guiado por el profesor Gleditsch ${ }^{48}$. Por otro lado, una data del semanario cuenta que el estatúder de las Provincias Unidas, durante su estancia en Brunswick, había visitado el gabinete de curiosidades, había examinado el arsenal y había asistido a una ópera italiana. De parecido tenor es la noticia que dice que el Príncipe Enrique de Prusia, en un viaje a las Provincias Unidas, comparte desayuno con el estatúder y la princesa real en el "gabinete de curiosidades naturales". En otra información se ve el interés por estos gabinetes en la época. Así, conocemos vía Gaceta que la Emperatriz Catalina II había mandado adquirir en Hamburgo un gabinete de historia natural valorado en veinte mil rublos. Por otro lado, el periódico refiere, en una noticia que participa las diferentes actividades de la familia real danesa, que ésta ha visitado el palacio de Rosenborg para ver el «Gabinete de curiosidades y medallas antiguas y modernas» ${ }^{49}$.

La Gaceta de Madrid también mostró interés en participar cuestiones de experimentalismo científico. Por ejemplo, refiere que dos miembros de la Academia Imperial de San Petersburgo, intentando emular las experiencias de Braun, Aepinus y Lomonosov de 1760, se habian desplazado a Arkhangelsk con el objetivo de congelar el mercurio artificialmente y así conocer el calibre del frío en esa latitud del mar Blanco, utilizándose para ello «Termómetros de Ayre, construidos según los fundamentos del señor Amontons" ${ }^{50}$. También cuenta la Gaceta en una noticia que, durante su estancia en Prusia, el diplomático otomano Achmet Efendi había observado aspectos de «filosofia experimental» en la Academia de Ciencias de Berlin, destacándose las experiencias eléctricas al cuidado de un hijo de Euler realizadas con instrumentos de Musschenbroek. En otra información se refiere que el diplomático de la Sublime Puerta, durante una visita a la Biblioteca berlinesa, habia verificado el sistema de Copérnico con un aparato que consistía en dos globos movidos por un reloj ${ }^{51}$. De otra índole es una data descriptiva de experimentación botánica: relata que en los jardines del palacio de Schönbrunn crece un nuevo género de plantas llamadas arbores dracones botanicorum, una suerte de palma con una rara flor no conocida por los botánicos, de cuyas caracteristicas el profesor de Medicina Grantz había publicado una disertación ${ }^{52}$.

Hay que señalar que el periódico oficial algunas veces selecciona informaciones de aspectos climáticos, en las que se detecta el afán por las mediciones. En esta línea, una noticia se hace eco del calor sufrido en Sajonia durante el verano

48 Gaceta... ก.॰ 6 del 7 de febrero de 1764 , data Berlin 10 de enero de 1764.

49 Gaceta... n. 43 del 27 de octubre de 1767, data La Haya 7 de octubre de 1767; Gaceta... n. ${ }^{\circ} 37$ del 13 de septiembre de 1768, data La Haya 24 de agosto de 1768; Gaceta... n. ${ }^{\circ} 31$ del 5 de agosto de 1766, data Hamburgo 8 de julio de 1766 y Gaceta... n. ${ }^{\circ} 19$ del 12 de mayo de 1767, data Copenhague 14 de abril de 1767.

50 Gaceta... n. ${ }^{\circ} 1$ del 6 de enero de 1761 , data Hamburgo 12 de diciembre de 1760.

${ }^{5 t}$ Gaceta... n. ${ }^{\circ} 6$ del 7 de febrero de 1764, data Berlín 10 de enero de 1764 y Gaceta... n. ${ }^{\circ} 10$ del 6 de marzo de 1764, data Berlin 7 de febrero de 1764.

${ }^{52}$ Gaceta... n. ${ }^{\circ} 31$ del 2 de agosto de 1768, data Viena 2 de julio de 1768. 
de 1767, añadiéndose que un físico había realizado mediciones con un termómetro Réaumur, y que se habían alcanzado durante el mediodía de los días 6 al 11 de agosto de aquel año niveles de temperatura de la "zona Tórrida". También el frío es protagonista de una data de la Gaceta: comenta que según los datos de las mediciones realizadas en el Real Colegio de Francia y en el Observatorio de la Marina "en cuatro termómetros bien arreglados", París no había sufrido un frío tan intenso desde 1709 como el verificado entre el 21 de diciembre de 1767 y el 8 de enero de 1768, puesto que "excedió en cuatro grados y medio al que hizo en 1740 y sólo difiere un grado del que tuvimos en 1709 „53.

La Gaceta de Madrid tiene interés en hacerse eco de forma concisa y enumerativa de las disertaciones leídas en las juntas públicas anuales de la Real Academia Geográfico-Histórica de Caballeros de Valladolid (1752), que se suelen celebrar el 4 de noviembre coincidiendo con la onomástica de Carlos III. Así, una primera noticia dice que Diego de Sierra había presentado una disertación acerca de los límites españoles y gallegos «en el Océano». En otra Gaceta se comunica que Miguel de Cevallos había disertado acerca de los reyes godos y del Fuero Juzgo, y que Vicente Villa lo habia hecho sobre el método para hallar la longitud geográfica. También el periódico, en una data que informa de otra junta anual, dice que Manuel de Guillamas había leído un discurso sobre la Historia y examen de opiniones de la «figura de la Tierra». En la misma línea informativa, una noticia cuenta que se había disertado acerca del Imperio de Marruecos según el viaje de Gonzalo de Cañas, así como sobre el estado de Valladolid. En otra reseña de parecida índole se señala que el Conde de Alva Real había pronunciado una disertación acerca de la cronologia de los primeros reyes de Aragón, y Vicente Villa una intitulada Cotejo de las observaciones modernas en las distancias, y velocidad de los Planetas sobre la infalibilidad de la regla de Keplero. Por último, una noticia refiere que Benito Verdesoto había pronunciado una disertación sobre el estudio militar de la cosmografía ${ }^{54}$.

El periódico oficial también refiere informaciones sobre las disertaciones de las instituciones europeas de orientación científica. Así, por ejemplo, una noticia de la Gaceta narra la visita rendida por Catalina II de Rusia a la Academia de Ciencias en el aniversario de su exaltación al Trono, enumerándose el programa: Aepinus lee en alemán un tratado sobre los «fenómenos" y sus efectos sobre la naturaleza, el profesor Zeiher diserta, también en alemán, acerca de los cristales fabricados en Rusia aptos para reverberar ciertos colores (especificándose que no se refieren a los conocidos del inglés Dollond); además se comprueban las ventajas de unas lunetas ópticas con aplauso de la emperatriz, y el profesor Rumovski lee una memoria sobre óptica en lengua rusa ${ }^{55}$.

53 Gaceta... n. ${ }^{\circ} 3$ del 19 de enero de 1768, data Dresde 5 de diciembre de 1767 y Gaceta... n. ${ }^{\circ} 4$ del 26 de enero de 1768, data París 8 de enero de 1768.

54 Gaceta... n. ${ }^{\circ} 46$ del 17 de noviembre de 1761; Gaceta... n. 45 del 11 de noviembre de 1766; Gaceta... n. 48 del 1 de diciembre de 1767; Gaceta... n. ${ }^{\circ} 47$ del 22 de noviembre de 1768; Gaceta... n. 47 del 21 de noviembre de 1769 y Gaceta... n. 47 del 20 de noviembre de 1770.

55 Gaceta... n. 36 del 6 de septiembre de 1763, data San Petersburgo 19 de julio de 1763. 
La Gaceta participa algunas informaciones de la Academia de Artillería de Segovia (1764), con clara intención de divulgar el programa curricular de la institución. Por ejemplo, una información refiere que en la Academia se van a instruir los cadetes en las ciencias matemáticas, en la artillería y en los demás conocimientos que pertenecen a "una educación sólida, útil y completa», para que sus oficiales se eduquen en "la escuela del honor y de la ciencia", añadiéndose que en la apertura pública de la institución el jesuita Eximeno, matemático y director de estudios, había pronunciado una oración acerca de la importancia del estudio teórico para desempeñar en la práctica el servicio de Su Majestad. Otra Gaceta informa de una sesión pública de matemáticas en la que un caballero cadete había defendido una oración sobre la necesidad de la geometría para el arte militar, y otros seis alumnos habian presentado unas proposiciones sobre cálculo y geometría. De parecido tenor es una noticia que refiere un examen público presidido por Muniáin, en el que los cadetes habían exhibido sus progresos en las disciplinas científicas, "sacándose por suerte los billetes" de las materias de Fisica y Matemáticas; también se habían explicado "planos, perfiles y elevaciones" de arquitectura militar ${ }^{56}$.

He seleccionado tres noticias del exterior que señalan sucintamente la orientación docente de las academias militares que se estaban creando en Europa. De esta forma, una noticia, tras aludir a la formación previa de una Compañía de Cadetes Nobles de Polonia y Lituania, refiere que se estaba bosquejando una Escuela Militar polaca, en cuyo currículo se incluirían como disciplinas: Idiomas, Geometría y Geografía. Por otro lado, la Gaceta informa en una data que la Academia de Reales Guardiamarinas de Nápoles había celebrado una sesión pública en la que se habian expuesto pormenores de geometría, esfera, navegación y artillería, añadiéndose que dicha institución había sido fundada por «el actual Monarca $\mathrm{Ca}$ tólico». Por último, el periódico comunica en una noticia que Portugal ha pedido a Inglaterra matemáticos y oficiales para la futura Academia Náutica y Militar lusa ${ }^{57}$.

La Gaceta de Madrid también refleja algunos aspectos de los intereses educativos del Setecientos en el relato periodístico protagonizado por el Real Seminario de Nobles de Madrid (1725). Así, una noticia nos cuenta que Carlos III y su familia habian asistido a unas conclusiones de matemáticas y física experimental en el Real Seminario de Nobles de Madrid, donde cuatro caballeros seminaristas las habían defendido con ayuda de "curiosas y selectas machinas". De parecido tenor es otra noticia que relata la visita realizada por los hijos de Carlos III al Real Seminario de Nobles de Madrid, destacándose que se habían parado en el "salón de las máquinas de Física Experimental» y que habían sido testigos de "útiles experiencias". Además anunció el semanario, en cuatro reseñas durante el periodo estudiado, los

56 Gaceta... n. 22 del 29 de mayo de 1764; Gaceta... n. ${ }^{\circ} 43$ del 22 de octubre de 1765 y Gaceta... n. ${ }^{\circ}$ 37 del 11 de septiembre de 1770 .

${ }^{57}$ Gaceta... n. 33 del 13 de agosto de 1765, data Varsovia 4 de julio de 1765; Gaceta... n. ${ }^{\circ} 5$ del 4 de febrero de 1766, data Nápoles 7 de enero de 1766 y Gaceta.. n. ${ }^{\circ} 49$ del 6 de diciembre de 1763, data Londres 15 de noviembre de 1763. 
cursos de "Physica Experimental» organizados por la mencionada institución, indicándose los días de la semana de las lecciones, el horario en que se impartían y los profesores a cuyo cargo estaban las clases (en una primera época el jesuita $\mathrm{Za}$ cagnini, después el padre Luis de San Maurín y Becar); también se decía que se seguirían los métodos y las experiencias que en Paris realizaba el abate Nollet ${ }^{58}$.

El periódico oficial tuvo empeño en constatar sobriamente algunas actividades de la Sociedad Bascongada de Amigos del País (1765) relacionadas con la renovación educativa y de saberes prácticos. De esta forma, una noticia de la Gaceta refiere unas «funciones púbiicas", en las que algunos jóvenes habían expuesto aspectos de las siguientes materias: Historia de las Buenas Letras, Historia de España, Cronología, Geografía de España y Física experimental. Otra información menciona que en Marquina, en septiembre de 1767, los alumnos de la Bascongada se habían examinado de Historia Sagrada, Geografía, Geometría, Elementos de álgebra, Geografía universal, Explicación de la esfera y Uso del globo. De otro tenor es una noticia de 1768, que nos dice que en la villa de Vergara se habían celebrado múltiples actividades, destacándose que se habian participado experiencias, observaciones y escritos de agricultura, de economía rústica, de arquitectura hidráulica, de mineralogía, de medicina, "y varia Erudición" ${ }^{59}$.

En la línea educativa aludida, la Gaceta de Madrid inserta anuncios de clases particulares. Por ejemplo, se señala que en la Posada del Príncipe el italiano Pinelli daba clases de arquitectura civil, militar, aritmética, "de toda clase de medidas»; asimismo enseñaba a dibujar y a "formar todo género de Planos de Campaña". De parecido modo, el periódico anuncia que un francés impartía lecciones de latín, francés, aritmética, álgebra, geometría, trigonometría y explicación de las experiencias físicas de Nollet; añadiéndose que su objetivo era fomentar el gusto por las ciencias, sin menoscabo de una buena crianza política y cristiana. Finalmente, la Gaceta refiere en una noticia que Luis Castellanos se encontraba en Madrid con el fin de ofertar sus servicios docentes, que incluian la enseñanza de los «Elementos de las principales ciencias naturales» y también latín y filosofía, que enseñaba "con un modo fácil, en poquísimo tiempo" 60 .

Ya hemos ido comentando algunos aspectos del tratamiento de las noticias seleccionadas. El periódico suele dar fe sucintamente de las actividades de los astrónomos y de los itinerarios que siguen para sus observaciones. Por otra parte, en la Gaceta hay un tratamiento sesgado de algunas cuestiones; se ve por ejemplo en el empeño en expresar el pujante valor de la colaboración científica, patente en las observaciones astronómicas y en los contactos de los sabios en lo tocante a la de-

58 Gaceta... n. ${ }^{\circ} 28$ del 8 de julio de 1760; Gaceta... n. 12 del 25 de marzo de 1766; Gaceta... n. 20 del 19 de mayo de 1761; Gaceta... n. ${ }^{\circ} 21$ del 25 de mayo de 1762; Gaceta... n. ${ }^{\circ} 21$ del 24 de mayo de 1763 y Gaceta... n. ${ }^{\circ} 19$ del 8 de mayo de 1764.

59 Gaceta... n. ${ }^{\circ} 20$ del 20 de mayo de 1766; Gaceta... n. ${ }^{\circ} 42$ del 20 de octubre de 1767 y Gaceta... n. ${ }^{\circ}$ 46 del 15 de noviembre de 1768.

60 Gaceta... n. 43 del 26 de octubre de 1762; Gaceta... n. ${ }^{\circ} 16$ del 17 de abril de 1764 y Gaceta... n. ${ }^{\circ}$ 48 del 29 de noviembre de 1768. 
terminación de la longitud en el mar; también se ve en el interés periodístico por participar la presencia regia en las actividades de los hombres de ciencia.

En algunos casos, llama la atención la precisión horaria en el relato periodisti$\mathrm{co}$, por ejemplo cuando se narra un eclipse de Sol; otras veces se pone de relieve el tono explicativo, verbigracia en una noticia francesa que comenta la utilidad de la observación del paso de Venus por el disco solar, señalándose que ayudará a conocer la distancia de la Tierra al Sol. En otros relatos, sin embargo, prima lo noticioso del descubrimiento de un cometa, o la descripción a vuelapluma de una aurora boreal. También se debe señalar que algunas noticias tienen interés en hacerse eco de los rigores climáticos, aludiendo a los excesos del tiempo (calor o frío) y a las mediciones de temperaturas, cuestiones que enlazan con dos aspectos típicos del XVIII: la percepción que tuvieron en la centuria de estar viviendo un siglo muy frío (con alusión al año 1709, considerado particularmente gélido) y, en segundo lugar, el empeño ilustrado por mensurar. Además, el lector de la época pudo familiarizarse, sólo sea nominalmente, con anteojos, telescopios, termómetros, péndolas, cronómetros, triangulación geodésica, etc.

En lo que respecta a las noticias de expediciones, aquéllas nos acercan a un gaceterismo escueto que participa el cometido de los viajes y algunos de sus resultados, aunque algunos lectores u oyentes, por ende, pudieron saber de la existencia de lugares lejanos, tener un conocimiento epidérmico de geografía gracias a la Gaceta, que busca muchas veces acercarse a un relato exacto cuando, por ejemplo, menciona la localización de una isla descubierta por Byron. Llama la atención, además, la difusión que tuvieron los viajes de la Rusia de Catalina Il y, también, que en el periódico se detecte la relación del viaje científico con la expansión territorial de los europeos. Asimismo, en el relato de algunas expediciones no se pasa por alto la mención a la presencia de dibujantes en las tripulaciones, lo que demuestra la renovada relación que tuvieron el dibujo y la ciencia en la época.

También, hemos comprobado que en algunas datas del apartado de las exploraciones hay alusiones de carácter etnográfico, como en el relato de los descubrimientos rusos de islas en la zona de Kamchatka, que describen a los habitantes de aquéllas como pertenecientes a la nación de los esquimales; o en las menciones que hace Bougainvilie de los isleños que ve en sus viajes, con elogiosos comentarios sobre sus costumbres; también se observa en la descripción de los indios de la expedición de Gaspar de Portolá, de los que se destacan sus virtudes, subyaciendo en estas informaciones la idea del buen salvaje.

Por otro lado, hay que subrayar la escasez de noticias acerca de la preparación de la expedición de Gaspar de Portolá a la Alta California. También hemos reparado en que las informaciones de la importante expedición danesa de Niebuhr hablan de sus objetivos, del itinerario, de algunos percances del viaje, de cuestiones administrativas y de algún aspecto científico (determinación geográfica de parte de las costas de Siria, verbigracia), pero en ninguna noticia se menciona a los otros 
expedicionarios (Von Haven, Kramer, Forsskäl y Baurenfeind), ni se alude a los enfrentamientos entre ellos.

En lo que respecta a los gabinetes de curiosidades, hay que destacar la importancia periodística de las visitas de cortesía de reyes y príncipes de la época a estas colecciones, enlazándose estas noticias con la intención de crear un ambiente propicio a estas colecciones en España, que dará sus frutos en 1771 con la creación del Real Gabinete de Historia Natural de Madrid.

Por otro lado, los discursos y disertaciones (prosa de ideas) de las academias científicas ilustradas son referidos a título de enumeración. En cuanto al tratamiento de las noticias de cuestiones docentes, ya del Real Seminario de Nobles de Madrid, ya de los exámenes de la Económica Bascongada, o bien de las pruebas de la Academia de Artilleria de Segovia, la publicación pone de relieve de forma escueta pero intencionada la necesidad de aunar los conocimientos teóricos y prácticos. Además, debe añadirse que el periódico incluye en algunas publicaciones anuncios de clases particulares, en los que también aflora la importancia de la nueva ciencia, viéndose, a través del lenguaje utilizado, un inequívoco tratamiento publicitario en el relato de estos avisos.

Finalmente, hay que destacar que el periódico, con un notable afán de rigor, suele mencionar casi siempre la profesión, cargo o instituciones a las que pertenecen los protagonistas de las noticias, contribuyendo, por otra parte, a la divulgación de los nombres de los científicos del tiempo (Delisle, Lalande, Messier, Lomonosov, Aepinus, Gleditsch, Rumovski, Solander, Euler, Nollet, Dollond, etc.).

\section{LA NOVEDAD: UTILIA Y CURIOSA}

El siglo XVIII se caracterizó por su pasión por las novedades, que en gran medida tuvieron que ver con el invento y con la máquina. En este contexto, la Gaceta de Madrid transmite el interés por una tecnología primitiva que, como comprobaremos a través de las noticias, suele estar relacionada con la utilidad pública. Así, el periódico se hace eco de variadas invenciones que mejoran las condiciones de vida: instrumentos hidráulicos, polígrafos multicopistas, etc.; todo ello en un momento en que la máquina es esencial como modelo del utilitarismo y de la mentalidad aplicada. También, la Gaceta está inmersa en la apuesta por la renovación naval típica del XVIII, reflejándose en noticias provenientes de Inglaterra y Holanda algunas mejoras, como el carenado de las embarcaciones con forros de cobre, $y$, también, difundiéndose a través de algún anuncio las ventajas de una brea nueva para calafatear los bastimentos; además fue noticioso para el periódico el método Poissonnier para desalar el agua marina, del que hay varias referencias en las datas francesas. Por otro lado, la Gaceta participa informaciones de artilugios para flotar, que revelan un afán por adaptarse a otros medios naturales. Finalmente, el interés tecnológico y científico de la época es patente en los anuncios del semanario, como comprobaremos al abordar su relato. 
También, la Gaceta de Madrid refiere noticias que se inscriben en un novedoso y actualizado gusto por el mundo clásico, por la Antigüedad, en la línea propugnada por el neoclasicismo, un territorio donde las excavaciones de Pompeya y Herculano operaron como un acicate en el estudio y redescubrimiento de lo clásico. Así, el periódico refleja el hallazgo de estatuas y monedas antiguas, comunica el descubrimiento de unas termas romanas y participa algunos regalos que se hacian en la época, de los que se infiere un interés por las culturas clásicas.

La Gaceta de Madrid tiene interés en relatar informaciones de máquinas relacionadas con ingenios hidráulicos, con aplicaciones industriales y con la construcción. Una primera noticia refiere que el padre Francisco Javier Transmontana, burgalés, ha inventado una máquina que bombea agua a 36 pies de altura, destacándose que sus aplicaciones en el campo deberían de ser buenas por "la poca costa que ofrece tan útil descubrimiento". En línea parecida, otra información dice que Fernando González de Lara, escultor y arquitecto residente en Burgos, ha construido un instrumento hidráulico que «moviéndole sin fatiga con sóla una mano" es capaz de subir agua a 68 pies, añadiéndose que el modelo podría ofrecer grandes utilidades. Por otra parte, una noticia francesa nos participa que en Versalles, $y$ en presencia de Luis XV, se había demostrado la eficacia de tres "bombas para incendios", de las que se destacaban las mejoras introducidas en lo que respecta a la mayor elevación en el tiro del agua y a la mayor cantidad de liquido que podían lanzar ${ }^{61}$. De otro tenor es una información de la Gaceta que menciona que en la Sociedad Bascongada se había examinado una novedad: la "máquina neumática" del socio agregado Manuel de Gamarra ${ }^{62}$. Además, la Gaceta reseña en una noticia que el arquitecto Hoffner recibe una gratificación por su invento, una máquina de utilidad en la construcción de calzadas y puentes, destacándose que el artefacto habia sido probado en el Danubio y que, con el concurso de aquél, dieciséis hombres podian hacer el trabajo que antes hacian doscientos ${ }^{63}$.

El periódico oficial participa una tipología de noticias en la que se presta atención a unas máquinas que facilitan la vida, y que suelen tener una utilidad más doméstica. De este modo, sabemos por una noticia que el señor Lorenzo, ingeniero y caballero de la Orden de San Miguel conocido por sus «obras útiles de mecánica", había presentado a la familia real francesa su invento, consistente en un brazo artificial que suplía los movimientos de las extremidades naturales perdidas, comentándose el beneficio de una invención «tan propia para consolar a la humanidad de las infelicidades de la guerra»; añadiéndose que el ingenio había sido aprobado por la Academia de Ciencias de París. Por otra parte, el periódico refiere informaciones de máquinas multicopistas. Así, sabemos gracias a una noticia que el Conde de Neuperg ha inventado una máquina conocida como el «co-

61 Gaceta... n. 40 del 2 de octubre de 1759; Gaceta... n. 13 del 25 de marzo de 1760 y Gaceta... n. 52 del 29 de diciembre de 1767, data París 14 de diciembre de 1767.

62 Gaceta... n. ${ }^{\circ} 20$ del 20 de mayo de 1766.

63 Gaceta... n. 9 del 1 de marzo de 1768, data Viena 1 de febrero de 1768 
pista secreto", capaz de mover dos, tres o más plumas a la vez, obteniéndose simultáneamente varias copias de lo que se estuviese escribiendo, apostillándose que para su buen uso llevaría instrucciones en francés y alemán, así como «figuras" que ayudarian a su entendimiento. De parecido tenor es una data que comunica que la Academia de Ciencias de París habia aprobado un invento de Coteneuve llamado el "polygrapho o hábil copista», que escribia tres copias a la vez, destacándose su facilidad para ser transportado. En otra noticia de la Gaceta, se reseña una máquina del padre Boissier: un artilugio que consigue el efecto de perfeccionar retratos en bajorrelieve mediante la manipulación de una llave. Por otro lado, una data refiere el invento del arquitecto Roland Le Virois, que había ideado un instrumento útil para la delineación en perspectiva sobre una superficie llana, para dibujar "geométricamente" sin que el usuario tuviera que saber ni dibujo ni geometría ${ }^{64}$.

La Gaceta se hace eco también de informaciones en las que el invento está relacionado con instrumentos de uso científico. Por ejemplo, refiere cómo Lalande y Leroy habian dado fe en la Real Academia de Ciencias de París de la buena factura de una nueva "armadura de telescopio» diseñada por el señor Navarra, de la que destacaban sus ventajas: la posibilidad de movimiento rápido y lento, el desplazamiento horizontal y vertical, independiente el uno del otro para comodidad del astrónomo; añadiéndose que el mencionado inventor también había ideado quitasoles de faltriquera de acero, sillas de faltriquera y otras «a manera de bastones», útiles en el campo o patios de comedias. Además, el periódico comenta en otra noticia que los hermanos Charost, relojeros parisinos residentes en Madrid, habian inventado un reloj de faltriquera, que destacaba por su precisión en la determinación de segundos y por la ayuda que prestaba en las observaciones astronómicas y de navegación ${ }^{65}$.

La Gaceta de Madrid informa de las mejoras técnicas navales en algunas noticias escuetas. Así, una noticia refiere que el Almirantazgo de Amsterdam aconseja revestir con planchas de cobre «amarillo y rojo" los navíos destinados a América. Además, otra información señala que los ingleses van a "forrar con planchas de cobre" el navío de guerra el Delfín y la chalupa Tamer. En una línea parecida de interés naval, una noticia dice que en Portsmouth se han realizado experiencias en las arboladuras de naves con maderas de la América septentrional. En otra data se destaca la visita del almirante Moore a los astilleros de Portsmouth, donde comprueba el carenado de los nuevos navios de guerra y conoce de primera mano el invento de una útil bomba para achicar el agua. De otro tenor náutico es una noticia veneciana que refiere que el abate Ventura ha inventado una má-

6* Gaceta... r. ${ }^{\circ} 1$ del 6 de enero de 1761, data París 20 de diciembre de 1760; Gaceta... n. 43 del 25 de octubre de 1763, data Viena 24 de septiembre de 1763; Gaceta... n. ${ }^{\circ} 5$ del 31 de enero de 1764, data Versalles 14 de enero de 1764; Gaceta... n. ${ }^{\circ} 35$ del 27 de agosto de 1765, data Compiègne 10 de agosto de 1765 y Gaceta... n. ${ }^{\circ} 2$ del 12 de enero de 1768, data Versalles 26 de diciembre de 1767.

65 Gaceta... n. ${ }^{\circ} 16$ del 17 de abril de 1770, data París 2 de abril de 1770 y Gaceta... n. 40 del 1 de octubre de 1765 
quina para purificar el aire de las embarcaciones, que se probaría en el navío de guerra El Buen Consejo ${ }^{66}$.

En relación con las mejoras navales, la Gaceta de Madrid mostró un especial interés por el método del médico y químico francés Poissonnier para desalar el agua del mar, recogiéndose seis noticias al respecto. Una primera información nos refiere que Poissonnier había ideado un método de destilación del agua del mar, que había sido probado en el puerto bretón de Lorient y en experiencias en alta mar, llegando el inventor a la conclusión de que el agua obtenida con su método era dulce y pura, y que, además, la máquina "no causa embarazo en el navío», con la ventaja de "hacer este servicio a la humanidad". Una segunda noticia dice que después de que se probara la salubridad del agua desalinizada en el barco Brillante, el rey de Francia había mandado instalar en sus navíos la máquina destilatoria. Además, la Gaceta informa en otra data de las experiencias potabilizadoras del agua del mar realizadas por Poissonnier en su casa, y en presencia de algunos nobles. Otra noticia se hace eco del método mencionado al comentar que el navío Duque de Praslin había utilizado la máquina de desalación durante cinco meses de navegación, proporcionando sesenta barricas de agua dulce. Por otra parte, una data del periódico refiere las repetidas probaturas "con feliz suceso" del artilugio desalinizador en el Mediterráneo francés, en el puerto de Toulon. Finalmente, sabemos gracias a una noticia de la Gaceta de la llegada al puerto de Saint-Malo de la fragata La Ceñuda, bajo las órdenes de Bougainville, destacándose que la expedición se habia beneficiado del agua destilada con la máquina de Poissonnier, que los polvos de limón de Faciot habian sido eficaces para combatir el escorbuto y que la ubicación de los hornos en el entrepuente había sido un acierto puesto que "han hecho el oficio de un ventilador por donde el aire se renovaba continuamente en el Navío" ${ }^{67}$.

La Gaceta de Madrid tuvo empeño en difundir informaciones sobre artefactos náuticos, que nos hacen pensar en un interés en la época por adaptarse al medio acuático. Así, una noticia comunica que en la Academia de Ciencias de Berlín se ha leído una memoria de Richter, intendente de fábricas del rey de Prusia, sobre su método para construir debajo del agua. Por otro lado, una data inglesa refiere que la Compañía para el Adelantamiento de las Artes. de las Manufacturas y del Comercio se había dignado aprobar el invento del señor Wilkinson, "una especie de casacas de corcho" que eran útiles para flotar. Además, una información procedente de Suecia nos cuenta que el señor Hallonquist, capitán de caballería, habia ideado un método para sostenerse en el agua sin saber nadar, cuya utilidad había

66 Gaceta... n. 20 del 17 de mayo de 1763, data Amsterdam 28 de abril de 1763; Gaceta... n. ${ }^{\circ} 23$ del 5 de junio de 1764, data Londres 15 de mayc de 1764; Gaceta... n. ${ }^{\circ} 1$ del 1 de enero de 1765, data Londres 7 de diciembre de 1764 y Gaceta... n. 37 del 15 de septiembre de 1767, data Venecia 4 de agosto de 1767 .

67 Gaceta... n. ${ }^{\circ} 44$ del 1 de noviembre de 1763, data Brest 5 de octubre de 1763; Gaceta... n. ${ }^{\circ} 30$ del 24 de julio de 1764, data Paris 9 de julio de 1764; Gaceta... n. 20 del 14 de mayo de 1765, data París 29 de abril de 1765; Gaceta... n. ${ }^{\circ} 24$ del 11 de junio de 1765, data Lorient 8 de mayo de 1765; Gaceta... n. ${ }^{\circ}$ 50 del 10 de diciembre de 1765 , data París 25 de noviembre de 1765 y Gaceta... n. ${ }^{\circ} 16$ del 18 de abril de 1769, data Saint-Malo 21 de marzo de 1769. 
sido verificada en agosto de 1765 en presencia de muchos circunstantes. De parecido tenor es otra noticia que participa que en La Haya se encuentra un inglés conocido por ser «inventor de máquinas para sostenerse sobre el agua con desembarazo", añadiéndose que las pruebas del artilugio se habian hecho en Scheveningen con asistencia del estatúder y que su utilidad era grande en ríos y en mares, ya que resistía la fuerza de las olas. En la misma línea, una data francesa relata que el abate de la Chapelle, miembro de la Real Sociedad de Londres, había confeccionado un «justillo de corcho", consistente en una suerte de corsé llamado scaphandre que servía para flotar en el agua, matizándose que era diferente de las casacas de corcho ya inventadas en Francia e Inglaterra; contándose, además, que el abate había inventado una especie de aleta natatoria, "guante a manera de pie de ganso", muy útil para la natación. Por último, una noticia detallada, narrativa y de tono curioso datada en Cádiz, refiere que el catalán Carlos Galup ofreceria una obra con láminas finas acerca de lo necesario que es saber nadar «sin apoyo de vejigas, ni otras máquinas", diciéndose que para demostrarlo se había tirado al mar "vestido y calzado, sin corchos", había buceado un rato y, tras emerger, "se desnudó como si sobre la cama se hallara»; a continuación, blandiendo papel, pluma y tintero había escrito unas líneas y había leído un libro, sacando luego la merienda, fumándose un cigarro y tocando la flauta; añadiéndose que se había invertido en todo ello una hora y diecinueve minutos ${ }^{68}$.

La Gaceta de Madrid siguió, a través de cuatro noticias, la convocatoria de un premio de la Sociedad Bascongada de Amigos del País para conseguir un barquín más apto para las ferrerias. Asi, una primera noticia de 1766 refiere que la Bascongada ha convocado un premio consistente en una medalla de oro valorada en mil reales, del que sería beneficiario quien determinara «por reglas geométricas fundadas en la experiencia" cuál de los tres barquines, el de cuero, el de tabla o el de trompas, era mejor para las ferrerías. Una segunda noticia de 1767 informa que no se ha presentado ningún escrito sobre el asunto de los barquines, por lo que "ha quedado sin aplicarse» el premio. Un año más tarde, en 1768, la Gaceta dice en otra información que el premio difiere su adjudicación, y que sólo ha habido «un concurrente» al mismo. Finalmente, en 1770 y sin mención al fuelle elegido, una data anuncia que el ganador del premio es P.C. Grignon, dueño de ferrerías en Champaña, y que se da un segundo premio a José Manuel de Goyri, constructor de ferrerías en Vizcaya ${ }^{69}$.

El periódico oficial inserta anuncios en los que vemos el interés tecnológico y científico de la centuria. Un primer aviso incluido en la Gaceta cuenta que Alejo del

68 Gaceta .. n. 47 del 20 de noviembre de 1764, data Berlín 20 de octubre de $1764 ;$ Gaceta... n. ${ }^{\circ} 49$ del 4 de diciembre de 1764, data Londres 10 de noviembre de 1764; Gaceta... n. 40 del 1 de octubre de 1765, data Estocolmo 23 de agosto de 1765; Gaceta... n. 45 del 5 de noviembre de 1765, data La Haya 16 de octubre de 1765; Gaceta... n. 32 del 11 de agosto de 1767, data París 27 de julio de 1767 y Gaceta... n. 37 del 15 de septiembre de 1767, data Cádiz 1 de septiembre de 1767.

69 Gaceta... n. ${ }^{\circ} 20$ del 20 de mayo de 1766; Gaceta... n. ${ }^{\circ} 42$ del 20 de octubre de $1767 ;$ Gaceta... n. ${ }^{\circ}$ 46 del 15 de noviembre de 1768 y Gaceta... n. ${ }^{\circ} 49$ del 4 de diciembre de 1770. 
Bosque y Murguía ha descubierto un modo de fundir la "Platina» que da como resultado "una masa sólida y homogénea", con propiedades como la dureza del hierro, el color blanco, que "no la corroen los ácidos simples», una flexibilidad parecida al bronce; señalándose asimismo sus posibles utilidades: para espejos de telescopios, timbres, escudos, medallas, "para el servicio de las viandas e instrumentos de cocina"; y diciéndose también que se espera conseguir el modo de perfeccionar su ductilidad, además de apostillarse que proviene de un mineral que se obtiene en las minas de oro de la provincia de Popayán, donde es conocido con el nombre de «Platina del Pinto". En otro anuncio de la Gaceta, de acusado tono publicitario, se da noticia al público de que en la carrera de San Jerónimo hay una fábrica de instrumentos ópticos, anteojos precisos y "microscopios para ver la circulación de la sangre", subrayándose la utilidad de éstos al decir: “... y en una rana se demuestra dicha circulación". De parecido tenor es otro aviso que anuncia que Juan Francisco Díaz, antiguo oficial de la "Fábrica de Cristales" que "sabe hacer óptica a la perfección", monta anteojos de larga vista, de teatro, etcétera, ofreciendo el óptico sus microscopios "para ver circular la sangre". Además, el periódico recoge dos breves avisos publicitarios de novedades sanitarias, en los que Carlos Jenty, profesor de Cirugia y Anatomía de Paris residente en Madrid, anuncia sus bragueros, útiles para la "curación de quebrados". Finalmente, un aviso se hace eco de «la prontitud con que el verdín y podredumbre destruyen las embarcaciones" y de la poca eficacia de la brea ordinaria, refiriéndose que en una "fábrica de embrear" de París se ha conseguido una utilísima composición, que puede adquirirse en Cádiz en casa de Juan Bautista Chillet, comerciante francés residente en España; comentándose que también vale el producto para pegar cuerpos sólidos de forma tan eficaz "que no es posible desprenderlos sino a fuerza de cincel y mazo" ${ }^{70}$.

La Gaceta de Madrid participa en tono curioso y enumerativo algunas informaciones acerca de los hallazgos arqueológicos de la época. Así, en una noticia se refiere que en Roma los padres de Santa Cruz de Jerusalén habían encontrado dos estatuas de bella factura, una de Perseo y otra de Andrómeda, y dos faunos "bien labrados", diciéndose que tal vez hubiera un anfiteatro en el lugar del hallazgo. Otra noticia señala que cerca de Albano se habian hallado tres estatuas, una mujer y dos guerreros, y que habían sido llevadas a Roma, pensándose que el escultor fuera griego a tenor de la inscripción. Por otro lado, sabemos por una data del semanario que, durante las excavaciones para reedificar un palacio del primado de Hungría, se había encoritrado una olla de barro con monedas de cobre y plata, cuya acuñación podria ser de época romana. Además, en otra información, la Gaceta dice que un labrador inglés habia hallado valiosas medallas romanas mientras se encontraba cavando cerca de la muralla de Newcastle. Por último, el periódico refiere en una noticia que a orillas del Neckar, en Ladenburg, se había

70 Gaceta... n. 51 del 18 de diciembre de 1764; Gaceta... n. 32 del 7 de agosto de 1764; Gaceta... n. ${ }^{\circ} 39$ del 27 de septiembre de 1768; Gaceta... n. ${ }^{\circ} 31$ del 2 de agosto de 1768; Gaceta... n. ${ }^{\circ} 44$ del 1 de noviembre de 1768 y Gaceta... n. ${ }^{\circ} 36$ del 3 de septiembre de 1765. 
descubierto un viejo baño romano en el que se distinguían los baños calientes, templados y fríos, así como la conducción y distribución de las aguas, habiendo sido el hallazgo digno de consideración de los "curiosos inteligentes"

También el periódico oficial selecciona algunas noticias en las que comprobamos una tipología de los regalos con los que se obsequiaba en la época, relacionados con el gusto por lo arqueológico y por los manuscritos antiguos. Conocemos así, vía Gaceta, que las Universidades de Oxford y Cambridge han enviado sendas cartas de agradecimiento al rey de las Dos Sicilias por su regalo, el tercer tomo de las Antigüedades de Heraclea, añadiéndose que los dos primeros tomos de esa colección habían sido obsequiados por Carlos III durante su reinado napolitano. De parecido modo, la Gaceta refiere en otra noticia que, en junta pública de la Real Academia Geográfico-Histórica de Caballeros de Valladolid, Bernardo de Sarriá ha pronunciado un discurso gratulatorio por el regalo recibido de Carlos III: Antigüedades de Herculano y Palacio de Caserta. Por otra parte, el periódico menciona en una data inglesa la llegada a Londres de un príncipe árabe comisionado para un negocio público, y que Jorge III había recibido un obsequio de aquél: un manuscrito "muy curioso y adornado" acerca de la Historia de Arabia. También, la Gaceta refiere en otra noticia que el embajador de Trípoli, que navegaba en ei navío El León entre Gibraltar y Portsmouth, llevaba un regalo cuyo destinatario era el rey de Inglaterra, y que consistía en una colección de manuscritos árabes antiguos y «curiosos" 72 .

Las novedades en forma de inventos se dan cita con frecuencia en la Gaceta de Madrid y suelen circunscribirse a una tecnología utilitarista, viéndose en el tratamiento de muchas noticias búsqueda de precisión. Así, encontramos con frecuencia informaciones descriptivas de un invento, noticias en las que se enumeran las características prácticas de una máquina. En esta línea, hay que destacar el tratamiento utilitarista de los artefactos acuáticos. Hay noticias en que se estimula la imaginación del lector o del oyente de la noticia, para que se haga cargo de cómo es el ingenio. Además, en algunos relatos el tratamiento informativo no olvida el carácter humanitario del artilugio, que conecta con los aires filantrópicos del XVIII; por ejemplo se ve en la data que refiere el brazo artificial ideado por el ingeniero francés Lorenzo, o cuando se subraya la utilidad del método desalinizador de Poissonnier para la humanidad. Asimismo, hay noticias del periódico en las que se ve una doble intención informativa; por ejemplo cuando se selecciona la data que refiere la máquina de Hoffner para construir calzadas y puentes, ya que se incluyen dos aspectos: uno es la gratificación que recibe el arquitecto, que conecta

71 Gaceta... n. ${ }^{\circ} 38$ del 16 de septiembre de 1760, data Génova 23 de agosto de 1760; Gaceta... n. ${ }^{\circ}$ 21 del 26 de mayo de 1761, data Génova 2 de mayo de 1761; Gaceta... n. 10 del 6 de marzo de 1764, data Viena 6 de febrero de 1764; Gaceta... n. ${ }^{\circ} 13$ del 1 de abril de 1766, data Londres 7 de marzo de 1766 y Gaceta... n. ${ }^{\circ} 8$ del 24 de febrero de 1767, data Mannheim 23 de enero de 1767.

72 Gaceta... n.. 18 del 4 de mayo de 1762, data Londres 9 de abril de 1762; Gaceta... n. ${ }^{\circ} 48$ del 29 de noviembre de 1763; Gaceta... n. ${ }^{\circ} 31$ del 30 de julio de 1765, data Londres 9 de julio de 1765 y Gaceta...n. 45 del 5 de noviembre de 1765, data Londres 11 de octubre de 1765. 
con el premio como estímulo ilustrado; y el segundo es la alusión a la eficacia aplicada del ingenio. Por otro lado, en los anuncios del capítulo debe destacarse el tratamiento publicitario y práctico de la información. Unas veces el relato es explicativo (como en el ejemplo de la platina); en otras ocasiones se acude a frases muy plásticas (es el caso de la brea como pegamento); incluso en algún aviso se llega al tono hiperbólico (por ejemplo: Juan Francisco Díaz que "sabe hacer óptica a la perfección").

Hay que señalar que, también en este capítulo de la novedad utilitarista, la Gaceta se esfuerza en reflejar la presencia de reyes y nobles en la presentación o probaturas de las máquinas, lo que nos da pie a pensar en la difusión que tuvieron las invenciones en la época. El periódico, además, pudo contribuir, al igual que en el caso de los científicos, a que se conociesen los nombres de los inventores: Poissonnier, Transmontana, Fernández de Lara, Neuperg, Coteneuve, Wilkinson, etc., debiéndose destacar de nuevo el empeño del periódico en constatar la profesión o cargo del inventor.

También, hay que comentar que el léxico que utiliza el periódico nos remite al ambiente científico y aplicado del momento: expresiones como "geométricamente", "por reglas geométricas fundadas en la experiencia" y, sobre todo, los términos "utilidad" y "utilidades" (estos dos últimos son los más usados en las descripciones del capítulo) así lo corroboran. Finalmente, llama la atención alguna omisión de la Gaceta, como en el caso del premio convocado por la Bascongada para optar por un barquín, ya que el semanario parece más preocupado por la convocatoria del premio que por referir el fuelle ganador, que no se menciona en el periódico.

En lo que respecta a las noticias de la novedad curiosa, interesa poner énfasis en que el tratamiento que dispensa la Gaceta a dicha información está en clave de curiosidad y empeño en dar fe de ella. El periódico selecciona un elenco de noticias en el que se ve un interés por lo arqueológico, por referir escuetamente los hallazgos en ruinas o excavaciones, e incardinado en el nacimiento de la arqueología científica.

\section{CONCLUSIÓN}

La Gaceta de Madrid no es un periódico científico ni tecnológico a primera vista. Sin embargo, espigando su información encontramos noticias de astronomía, expediciones, experimentos, academias, inventos, hallazgos arqueológicos, etc. El relato informativo de las cuestiones aludidas es variado: unas veces es epidérmico, en otras ocasiones es más abundoso y descriptivo, en otras narraciones hay un cariz publicitario muy marcado.

Por otro lado, del análisis del periódico se infieren las siguientes líneas maestras conectadas con el pensamiento del Setecientos: la colaboración científica 
entre los sabios europeos (patente en las observaciones de los pasos de Venus por el disco solar o en los contactos de los sabios para estudiar la determinación de la longitud marítima), el creciente papel de las academias y de la prosa de ideas, el experimentalismo, el apoyo de las monarquías a algunas actividades de la ciencia (hemos visto cómo algunos reyes reciben mapas, acompañan a los astrónomos en sus observaciones señeras y financian exploraciones científicas como las de Catalina II de Rusia o la danesa de Niebuhr), la institucionalización de las expediciones (enlazada con el interés científico y con la expansión territorial de las potencias europeas), el empeño de las monarquías en el conocimiento geográfico (visible en las noticias de contenido cartográfico), así como la renovación educativa llevada a cabo por las instituciones que se crean en el siglo ilustrado.

Además, la Gaceta está relacionada con otras claves culturales del xvIII: la creciente importancia de la tecnología utilitarista y la curiosidad por saber de algunos descubrimientos de objetos de épocas antiguas. Así, el elenco de noticias seleccionadas en el capítulo de la novedad (utilia) se ciñe preferentemente a la divulgación de máquinas, que obedece a un momento de interés por ellas como paradigma de la mecánica y la hidráulica, y que culminará con la creación del Real Gabinete de Máquinas en 1791, bajo la dirección de Agustín de Betancourt. Asimismo, es obvia la preocupación de los gobernantes del Setecientos por las mejoras navales, reconocible en la difusión de noticias con los carenados de cobre como contenido, o en los anuncios de las nuevas breas para calafatear. Por otro lado, la novedad curiosa tiene empeño en divulgar informaciones de contenido arqueológico claramente inscritas en su época, ya que no es casual que Carlos III ejerciera un importante mecenazgo en las excavaciones de Pompeya y Herculano durante su época de rey de las Dos Sicilias, las cuales avivaron el interés por lo arqueológico, sin olvidar que el neoclasicismo y figuras como Johann Joachim Winckelmann o Giambattista Piranesi van a poner los cimientos de la arqueología científica.

Debiera apostillar que en algunas noticias, de forma solapada a la información principal, se detectan otros pormenores. Por ejemplo, en el relato que aborda mediciones de las temperaturas extremas (calor o frío) hay una latente preocupación climática, típica en un siglo XVIII que pasó por ser de frío riguroso; o en el seguimiento del premio que convocó la Bascongada para mejorar los barquines de las ferrerías, en el que vemos que hubo años en que quedó desierto el premio o no se presentó ningún escrito, lo que nos lleva a pensar en el escaso ambiente tecnológico, o en las dificultades de difusión del premio, que, por otra parte, es recogido por el periódico como estímulo típico ilustrado. También hay que subrayar que las noticias seleccionadas para el trabajo son casi todas foráneas, lo que nos hace pensar en cierto cosmopolitismo, evidente en el interés de la Gaceta por lo que acontece en el exterior; pero también en una actitud mimética relacionada con el atraso español en algunas disciplinas aplicadas, pareciendo a veces que el extranjero se propone como modelo a imitar. 
Por todo ello, la información seleccionada no es neutral, sino que está inscrita en la elección orientada de noticias que sustenta nuestra hipótesis. Más incluso, es patente que hay un programa periodístico encaminado a difundir este tipo de noticias; además el periódico pudo contribuir a remover los obstáculos en el plan de propagación de los axiomas ilustrados estudiados, ya que, como se apuntó en la introducción, la tirada del periódico y su estabilidad temporal (sólo sea en comparación con otras publicaciones), su vinculación al poder y la lectura en voz alta le otorgaron un papel valioso en el entramado cultural de la época. Podemos decir, en suma, que la Gaceta de Madrid en el periodo 1759-1770 es algo más que el trazo grueso de la información oficial. 